\title{
Update Breast Cancer 2019 Part 3 - Current Developments in Early Breast Cancer: Review and Critical Assessment by an International Expert Panel
}

\section{Update Mammakarzinom 2019 Teil 3 - aktuelle Entwicklungen bei der kurativen Behandlung von Mammakarzinompatientinnen: eine Übersicht und Bewertung durch ein internationales Expertenpanel}

\section{(ㄷ) (1) (오 $\ominus$}

Authors

Hans-Christian Kolberg ${ }^{1}$, Andreas Schneeweiss ${ }^{2}$, Tanja N. Fehm ${ }^{3}$, Achim Wöckel ${ }^{4}$, Jens Huober ${ }^{5}$, Constanza Pontones ${ }^{6}$, Adriana Titzmann ${ }^{6}$, Erik Belleville ${ }^{7}$, Michael P. Lux ${ }^{8}$, Wolfgang Janni ${ }^{5}$, Andreas D. Hartkopf ${ }^{9}$, Florin-Andrei Taran ${ }^{9}$, Markus Wallwiener ${ }^{10}$, Friedrich Overkamp ${ }^{11}$, Hans Tesch ${ }^{12}$, Johannes Ettl ${ }^{13}$, Diana Lüftner ${ }^{14}$, Volkmar Müller ${ }^{15}$, Florian Schütz ${ }^{10}$, Peter A. Fasching ${ }^{6}$, Sara Y. Brucker ${ }^{9}$

\section{Affiliations}

1 Department of Gynecology and Obstetrics, Marienhospital Bottrop, Bottrop, Germany

2 National Center for Tumor Diseases, Division Gynecologic Oncology, University Hospital and German Cancer Research Center Heidelberg, Heidelberg, Germany

3 Department of Gynecology and Obstetrics, University Hospital Düsseldorf, Düsseldorf, Germany

4 Department of Gynecology and Obstetrics, University Hospital Würzburg, Würzburg, Germany

5 Department of Gynecology and Obstetrics, Ulm University Hospital, Ulm, Germany

6 Erlangen University Hospital, Department of Gynecology and Obstetrics, Comprehensive Cancer Center ErlangenEMN, Friedrich-Alexander University Erlangen-Nuremberg, Erlangen, Germany

7 ClinSol GmbH \& Co KG, Würzburg, Germany

8 Kooperatives Brustzentrum Paderborn, Klinik für Gynäkologie und Geburtshilfe, Frauenklinik St. Louise, Paderborn, St. Josefs-Krankenhaus, Salzkotten, Germany

9 Department of Obstetrics and Gynecology, University of Tübingen, Tübingen, Germany

10 Department of Obstetrics and Gynecology, University of Heidelberg, Heidelberg, Germany

11 OncoConsult Hamburg GmbH, Hamburg, Germany

12 Oncology Practice at Bethanien Hospital Frankfurt, Frankfurt, Germany

13 Department of Obstetrics and Gynecology, Technical University of Munich, School of Medicine, Klinikum rechts der Isar, Munich, Germany

14 Charité University Hospital, Campus Benjamin Franklin, Department of Hematology, Oncology and Tumour Immunology, Berlin, Germany

15 Department of Gynecology, Hamburg-Eppendorf University Medical Center, Hamburg, Germany
Key words

early breast cancer, adjuvant therapy, neoadjuvant therapy, St. Gallen panel of experts

Schlüsselwörter

frühes Mammakarzinom, adjuvante Therapie, neoadjuvante Therapie, St.-Gallen-Expertenpanel

received $\quad 1.4 .2019$

accepted 1.4.2019

Bibliography

DOI https://doi.org/10.1055/a-0887-0861

Geburtsh Frauenheilk 2019; 79: 470-482 @ Georg Thieme

Verlag KG Stuttgart · New York | ISSN 0016-5751

Correspondence

Peter A. Fasching, MD

Erlangen University Hospital, Department of Gynecology and Obstetrics, Comprehensive Cancer Center Erlangen EMN, Friedrich Alexander University of Erlangen-Nuremberg Universitätsstraße 21-23, 91054 Erlangen, Germany peter.fasching@uk-erlangen.de

$\Theta$ Deutsche Version unter: https://doi.org/10.1055/a-0887-0861 Supporting Information: https://doi.org/10.1055/a-0887-0861 


\section{ABSTRACT}

The treatment of breast cancer patients in a curative situation is special in many ways. The local therapy with surgery and radiation therapy is a central aspect of the treatment. The complete elimination of tumour cells at the site of the primary disease must be ensured while simultaneously striving to keep the long-term effects as minor as possible. There is still focus on the continued reduction of the invasiveness of local therapy. With regard to systemic therapy, chemotherapies with taxanes, anthracyclines and, in some cases, platinum-based chemotherapies have become established in the past couple of decades. The context for use is being continually further defined. Likewise, there are questions in the case of antihormonal therapy which also still need to be further defined following the introduction of aromatase inhibitors, such as the length of therapy or ovarian suppression in premenopausal patients. Finally, personalisation of the treatment of early breast cancer patients is also being increasingly used. Prognostic tests could potentially support therapeutic decisions. It must also be considered how the possible use of new therapies, such as checkpoint inhibitors and CDK4/6 inhibitors could look in practice once study results in this regard are available. This overview addresses the backgrounds on the current votes taken by the international St. Gallen panel of experts in Vienna in 2019 for current questions in the treatment of breast cancer patients in a curative situation.

\section{Introduction}

In the last couple of decades, there has been a significant improvement in the treatment and early detection of breast cancer. In addition to the introduction of new therapies, a structural improvement in patient care has also largely been responsible for improving the prognosis. Therapeutic recommendations, guidelines, participation in studies and certification processes can be named in this connection [1-7]. A better prognosis or better therapeutic efficacy has been able to be demonstrated for guideline-compliant treatment [3], treatment at certified breast centres [7] as well as for patients with study participation $[4,6]$. In view of this, it is of particular importance that, in an interdisciplinary framework, therapeutic recommendations are revised again and again, studies are reinterpreted, and the results of this discussion are disseminated. The current therapeutic recommendations of the German committee for the treatment of breast cancer patients (AGOMamma) were only recently published [8] and the $\$ 3$ guidelines were most recently updated in December 2017 [1,2]. On the international level, the St. Gallen conference, in which views and experiences are exchanged every two years and current issues are discussed and voted on, is of particular importance for the international exchange of interpretations of medical issues with regard to early, non-metastatic and thus curative breast cancer. In view of the therapeutic recommendations mentioned and the St. Gallen

\section{ZUSAMMENFASSUNG}

Die Behandlung von Mammakarzinompatientinnen in der kurativen Situation ist in vielfacher Hinsicht besonders. Hierbei ist die lokale Therapie mit Operation und Strahlentherapie zentraler Aspekt der Behandlung. Ziel ist eine komplette Elimination aller Tumorzellen am Ort der Primärerkrankung bei gleichzeitigem Bestreben, die Langzeitfolgen so gering wie möglich zu halten. Die immer weitere Reduktion der Radikalität der Lokaltherapie steht auch weiterhin im Blickpunkt. In Bezug auf die Systemtherapie haben sich in den letzten beiden Jahrzehnten Chemotherapien mit Taxanen, Anthrazyklinen und teilweise auch platinhaltigen Chemotherapien etabliert. Der Kontext der Nutzung wird immer genauer definiert. Ebenso gibt es bei der antihormonellen Therapie Fragen, die auch nach Einführung der Aromatasehemmer immer noch weiter definiert werden müssen, wie beispielsweise die Länge der Therapie oder die ovarielle Suppression bei prämenopausalen Patientinnen. Letztendlich soll die Behandlung von frühen Mammakarzinompatientinnen immer personalisierter werden. Prognostische genexpressionistische Tests könnten möglicherweise Therapieentscheidungen unterstützen. Ebenso muss überlegt werden, wie ein möglicher Einsatz von neuen Therapien wie Checkpointinhibitoren und CDK4/6-Inhibitoren in der Praxis aussehen könnten, sobald hier Studienergebnisse vorliegen. Diese Übersichtsarbeit beschäftigt sich mit den Hintergründen zu aktuellen Abstimmungen, die das internationale St.-Gallen-Expertenpanel in Wien 2019 für aktuelle Fragen in der Behandlung von Mammakarzinompatientinnen in der kurativen Situation vorgenommen hat.

conference, current aspects of clinical breast cancer research for patients with early breast cancer will be presented in this overview. The votes published here, which reflect the opinion of international experts, do not always comply with national therapeutic recommendations and guidelines. For a discussion of the voting results in view of German therapeutic recommendations and guidelines, we refer to Untch et al.

\section{Genetic Testing for Germ Line Mutations}

It is known that a significant proportion of the familial breast cancer risk is caused by mutations in high- and moderate-penetrance genes and genetic variants in low-penetrance genes. While until recently, only $B R C A 1$ and $B R C A 2$ were considered when testing for germ line mutations, the role of so-called panel genes has become better understood in recent years [9-12]. In addition, considerable efforts have been made in studies with more than 400000 patients in order to be able to validate the low-penetrance variants. In $>$ Fig. 1 , the timelines and the known contribution of the genetic mutations and variants in each case are described [13-19]. While BRCA1 and BRCA2 are responsible for approx. $16 \%$ of the twice-as-high familial breast cancer risk, another $4 \%$ can be explained by the panel genes (such as PALB2, CHEK2, BARD1) and others. To date, over 170 common and low-penetrance gene loci have been described which explain another $18 \%$ 
of the breast cancer risk [13-19]. Thus somewhat less than $40 \%$ of the twice-as-high familial breast cancer risk can be explained by genetic changes. Molecular subtypes and other risk factors such as the mammographic density are increasingly also integrated In the risk calculations $[11,13,20-26]$.

While most germ line changes which have been associated with breast cancer have no systemic therapeutic consequence, efficacy of the PARP inhibitors olaparib and talazoparib was established for HER2-negative patients with advanced breast cancer and a germ line mutation in BRCA1 or BRCA2 $[27,28]$. Studies in the neoadjuvant or adjuvant therapy of early breast cancer are being performed and they are still waiting to be published. In early breast cancer patients, it is known that patients with a BRCA1/2 mutation in the case of neoadjuvant chemotherapy have a greater chance of a pCR $[19,29,30]$. Likewise there is evidence that women with a BRCA1/2 mutation have a somewhat better prognosis following chemotherapy than patients without a mutation [29,31].

General questions on genetic testing were voted on by the St. Gallen panel (StGP). In patients with early breast cancer, the experts appeared to orient themselves on the recommendations for predictive genetic diagnostics. The results are summarised in $\downarrow \mathbf{T a}$ ble 1. In view of a therapeutic option for metastatic patients with triple-negative disease, a clearer positioning of the panel in favour of testing of all patients with TNBC would have been desirable here. However, the panel oriented itself on the expected mutation rates and therefore issued only a strong recommendation for testing patients with TNBC under the age of 60. In Germany, this results in a window of 10 years, between age 50 and 60, in which testing is recommended but is not covered by health insurance.

\section{Local Therapy - Surgery and Radiation Therapy Can Still Be Optimised}

Historically, the local treatment of breast cancer has been characterised by a markedly aggressive approach [32,33]. However, the introduction of concepts which connect radiation therapy and surgery have decisively shaped the local treatment of breast cancer, as the introduction of breast-conserving therapy has shown $[34,35]$. Unlike almost no other therapeutic method, attempts are made in the case of local therapy to continuously minimise the intervention in order to reduce long-term consequences as much as possible while preserving oncological security. A series of votes by the StGP also determined this basic principle.

Even if the radicality of the axilla surgery has already been significantly reduced through the introduction of sentinel lymph node removal, knowledge on the prognosis of some patient groups now already indicates that in some cases, the axillary surgery can be completely eliminated. Whether this approach is acceptable in the case of patients with clinically unremarkable axilla and negative axillary ultrasound is currently being clarified in three clinical studies [36-38].

A whole series of studies addressed the question of what is the best approach in the case of a positive sentinel lymph node. Several studies (IBCSG 23-01, AMAROS, ACOSG Z0011) were able to show for patients with breast-conserving therapy and subsequent radiation that, under certain conditions, complete axillary lym-

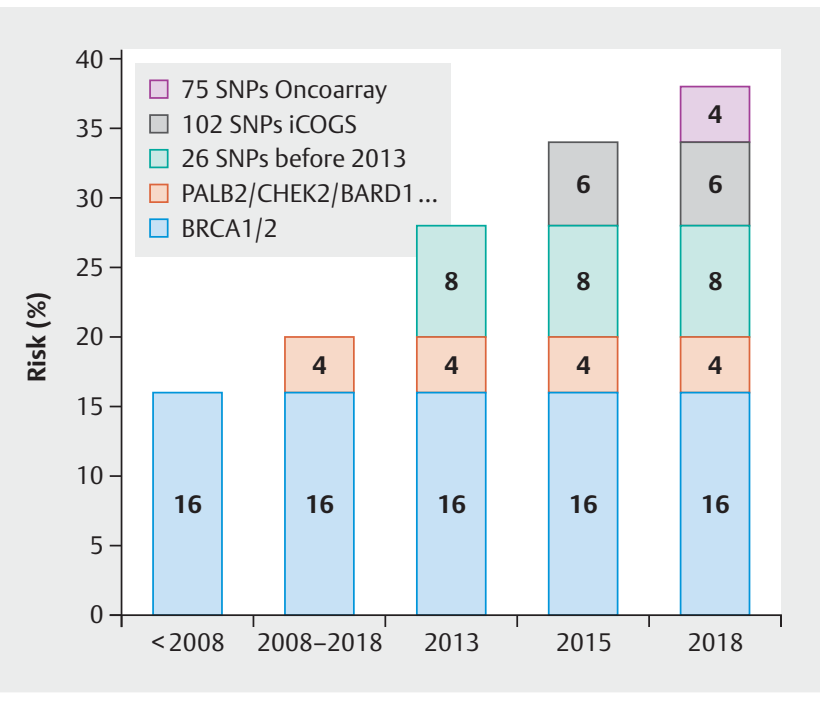

- Fig. 1 Explainability of the twice-as-high familial risk by breast cancer risk genes (high-penetrance genes, moderate-penetrance genes and low-penetrance variants, according to [13-18]).

- Table 1 Vote on the indication of high-penetrance germ line mutations. There were 53 voting experts; the number of those who did not vote is not known.)

High risk germline mutations

Genetic testing for high risk mutations after counselling should be considered in:

\begin{tabular}{|l|c|}
\hline All women with breast cancer: & \\
\hline - Yes & $29.2 \%$ \\
\hline - No & $70.8 \%$ \\
\hline - Abstain & $0 \%$ \\
\hline Patients with a strong family history: & \\
\hline - Yes & $100 \%$ \\
\hline - No & $0 \%$ \\
\hline - Abstain & $0 \%$ \\
\hline Patients under 35 at diagnosis: & \\
\hline - Yes & $95.9 \%$ \\
\hline - No & $4.1 \%$ \\
\hline - Abstain & $0 \%$ \\
\hline Patients under 50 at diagnosis: & \\
\hline - Yes & $32.7 \%$ \\
\hline - No & $65.3 \%$ \\
\hline - Abstain & $2 \%$ \\
\hline Patients under 60 with TNBC: & \\
\hline - Yes & $85.4 \%$ \\
\hline - No & $14.6 \%$ \\
\hline - Abstain & $0 \%$ \\
\hline Patients with TNBC at any age: & $38.8 \%$ \\
\hline - Yes & $2 \% .2 \%$ \\
\hline - No & \\
\hline - Abstain & \\
\hline
\end{tabular}


phadenectomy in the case of positive sentinel lymph nodes can be eliminated [39-43]. There are considerably fewer data in the case of patients with positive SNL following mastectomy, even if the IBSCG 23-01 and the AMAROS study admitted patients with mastectomy. Knowledge regarding the safety of this approach following neoadjuvant chemotherapy is likewise limited. In view of these data, the experts of the StG panel voted on several questions in this connection ( $\vee$ Table 2 ).

There are only very few data on the question of resection margins, particularly in the case of concomitant DCIS. Here the assessments of the panel of experts are helpful and may help avoid subsequent resection.

Other questions which the StGP addressed include the indication for radiation following mastectomy, hypofractionated radiation, the integration of oncoplastic surgeries and regional lymph node irradiation (RNI). All of the questions and answers can be found in the supplement Table S1.

\section{Chemotherapy or No Chemotherapy - Determination of Molecular Markers and Multigene Expression Tests}

While the indication for patients with TNBC and HER2-positive tumours is relatively clearly regulated by the guidelines and therapeutic recommendations, the question often arises in routine clinical practice as to which patients with HR-positive, HER2-negative breast cancer should be treated with adjuvant or neoadjuvant chemotherapy. It is clear that there are tumours in this group of patients which do not respond well to chemotherapy [44-46]. It is also known that some patients in this group have an extremely good prognosis. Given this, there is the question of the extent to which multigene tests can help in making a decision. For two multigene tests, there are studies which have attempted to include the use of their prognostic significance in therapy algorithms [47, 48]. Both studies were able to identify patient collectives whose prognosis was sufficiently good that the benefit of chemotherapy could not be proven or it was questionable whether chemotherapy was necessary. The use of chemotherapy in breast cancer patients has significantly decreased in recent years [49]. Part of this decrease was attributed in a U.S. study on node-positive patients to the use of multigene tests, even if the largest proportion of the decrease in the use of chemotherapy could not be explained by the decision-making aid of a multigene test [49]. The vote regarding some clinically relevant questions is summarised in $>$ Table 3 .

\section{Immunological Diagnostics in Early Breast Cancer}

In the metastatic therapy situation, efficacy has already been able to be demonstrated for immunotherapy with the PD-L1 checkpoint inhibitor atezolizumab [50]. Triple-negative patients whose immune cells in the tumour demonstrated an expression of PD-L1 had better progression-free survival and better overall survival in the case of combination therapy consisting of nab-paclitaxel and
- Table 2 Vote regarding the coordination between axillary surgery and radiation. There were 53 voting experts; the number of those who did not vote is not known.)

Radiotherapy approach in patients with macrometastatic SLN that did not undergo ALND

In a patient with a tumour below $5 \mathrm{~cm}$ and $1-2$ positive SLNs that has undergone a breast conserving procedure and is scheduled for whole breast irradiation ("Z11 criteria"):

- This patient can be treated with whole breast $41.70 \%$ irradiation without 3 rd/additional axillary field/high tangents.

- Additional axillary radiation should be added $29.20 \%$ in all cases.

- Additional axillary radiation should be added in cases of aggressive histologies/subtypes such as TNBC.

- Abstain $4.20 \%$

Surgery of the Axilla: postmastectomy

Based on e.g. the AMAROS trial and other data sets, the preferred approach for women with $\mathrm{T} 1-2$ cancers undergoing mastectomy and SLN mapping with macro-metastases in 1-2 sentinel nodes should be (assuming standard systemic adjuvant therapy):

\begin{tabular}{|c|c|}
\hline - No additional therapy to the axilla & $12.50 \%$ \\
\hline - Completion axillary dissection & $16.70 \%$ \\
\hline - Axillary/RNI per AMAROS & $47.90 \%$ \\
\hline - Depends on tumour biology (e.g. ER+ vs. TN) & $8.30 \%$ \\
\hline - Abstain & $14.60 \%$ \\
\hline \multicolumn{2}{|l|}{ ALND in patients with macrometastatic SLN } \\
\hline \multicolumn{2}{|l|}{ ALND can be omitted in: } \\
\hline \multicolumn{2}{|l|}{$\begin{array}{l}\text { ALND can be omitted in mastectomy with } 1-2 \text { positive } \\
\text { SNs, TNBC and RNI planned: }\end{array}$} \\
\hline - Yes & $70.80 \%$ \\
\hline - No & $22.90 \%$ \\
\hline - Abstain & $6.20 \%$ \\
\hline \multicolumn{2}{|l|}{$\begin{array}{l}\text { ALND can be omitted in mastectomy with } 1-2 \text { positive } \\
\text { SNs and chest wall but not RNI planned: }\end{array}$} \\
\hline - Yes & $19.10 \%$ \\
\hline - No & $66 \%$ \\
\hline - Abstain & $14.90 \%$ \\
\hline \multicolumn{2}{|l|}{$\begin{array}{l}\text { ALND can be omitted in mastectomy with } 1-2 \text { positive } \\
\text { SNs, ER+ and HER2+, and RNI planned: }\end{array}$} \\
\hline - Yes & $83.30 \%$ \\
\hline - No & $8.30 \%$ \\
\hline - Abstain & $8.30 \%$ \\
\hline \multicolumn{2}{|l|}{$\begin{array}{l}\text { ALND can be omitted in patients with tumours }>5 \mathrm{~cm} \\
\text { undergoing BCT with } 1-2 \text { positive } S N \text { s and undergoing } \\
\text { WBI: }\end{array}$} \\
\hline - Yes & $34.80 \%$ \\
\hline - No & $60.90 \%$ \\
\hline - Abstain & $4.30 \%$ \\
\hline
\end{tabular}


- Table 2 Vote regarding the coordination between axillary surgery and radiation. There were 53 voting experts; the number of those who did not vote is not known.) (Continued)

ALND can be omitted in patients with tumours $>5 \mathrm{~cm}$ undergoing BCT with 1-2 positive $\mathrm{SNs}$ and undergoing WBI breast and nodal radiation planned:

\begin{tabular}{|l|r|}
\hline - Yes & $73.90 \%$ \\
\hline - No & $21.70 \%$ \\
\hline - Abstain & $4.30 \%$ \\
\hline
\end{tabular}

Mastectomy with 3 positive nodes out of 3 removed and planned RNI:

- Yes not available

- No not available

- Abstain

not available

Use of SLND in cN1 undergoing PST

In a patient who is clinically node positive (CN1) at presentation and downstages to CNO after neoadjuvant therapy, SLN can substitute for ALND if:

\section{1-2 negative SLNs obtained:}

- Yes

$54.20 \%$

- No

$43.80 \%$

- Abstain

$2.10 \%$

3 or more negative SLNs obtained:

- Yes $91.70 \%$

- No $4.20 \%$

\section{- Abstain}

A clipped (marked) node, with or without additional SLNs is removed and is negative:

- Yes

$43.80 \%$

- No

- Abstain

$12.50 \%$

A clipped (marked) node, with additional SLNs is removed and is negative:

- Yes

$92.10 \%$

- No

$5.30 \%$

- Abstain

$2.30 \%$

ALND after PST when there is residual axillary disease In a patient who is $\mathrm{CN} 1$ at presentation and has a good clinical response; SLN mapping identifies 3 SLN:

ALND may be avoided if there is limited involvement with micrometastasis in one positive node only (no radiotherapy planned):

- Yes

- No

$63.80 \%$

- Abstain

$10.60 \%$
- Table 3 Votes relating to multigene tests. There were 53 voting experts; the number of those who did not vote is not known.)

\section{Multigene signatures and chemotherapy decision} making in ER+ HER2- tumours

In T1/T2, N0 cancers, genomic assays are valuable for determining whether to recommend chemotherapy?

- Yes

$93.60 \%$

- No

$4.30 \%$

- Abstain

$2.10 \%$

In T3 NO cancers, genomic assays are valuable for determining whether to recommend chemotherapy:

\begin{tabular}{|l|r|}
\hline - Yes & $74.50 \%$ \\
\hline - No & $21.30 \%$ \\
\hline - Abstain & $4.30 \%$ \\
\hline
\end{tabular}

In T any (1-3+LN), genomic assays are valuable for determining whether to recommend chemotherapy?

\begin{tabular}{|l|l|}
\hline " Yes & $78.70 \%$ \\
\hline - No & $17 \%$ \\
\hline - Abstain & $4.30 \%$ \\
\hline
\end{tabular}

\section{TAILORx and beyond: recurrence scores $\leq 25$}

The 21-gene recurrence score, if available, is widely used to assist adjuvant chemotherapy decisions, and that based on TAILORx, women with node-negative cancers and recurrence scores $\leq 25$ do not need chemotherapy

Women of age $<50$ with node negative cancer and RS 21-25 should receive:

- Chemo+ET

$41.70 \%$

- OFS + ET

$25 \%$

- Chemo + OFS + ET $10.40 \%$

- Tamoxifen only

$16.70 \%$

- Abstain

$6.20 \%$

Postmenopausal women with node-negative cancers and $\mathrm{RS} \geq 26$

Postmenopausal women with node-negative cancers and RS > 26 should be offered chemotherapy:

\begin{tabular}{l|l|}
\hline - Routinely & $38.80 \%$ \\
\hline $\begin{array}{l}\text { - In selected settings depending on other histo- } \\
\text { pathologic characteristics and patient references }\end{array}$ & $57.10 \%$ \\
\hline
\end{tabular}

\begin{tabular}{|l|l|}
\hline - Never & $0 \%$ \\
\hline - If score is greater than 30 only & $4.10 \%$ \\
\hline - Abstain & $0 \%$ \\
\hline Recurrence score in LN+ (PlanB trial) & \\
\hline
\end{tabular}

$\mathrm{RS}<11$ or equivalent in women of age $>50$ years and 1-2 positive $L N$ may be used to recommend against chemotherapy:

\begin{tabular}{|l|r|}
\hline - Yes & $78.70 \%$ \\
\hline - No & $14.90 \%$ \\
\hline - Abstain & $6.40 \%$ \\
\hline
\end{tabular}

Continued next page 
- Table 3 Votes relating to multigene tests. There were 53 voting experts; the number of those who did not vote is not known.) (Continued)

\section{Mammaprint in LN+ (based on MINDACT)}

Mammaprint low in women of age $>50$ years and 1-2 positive $L N$ may be used to recommend against the indication for adjuvant chemotherapy:

\begin{tabular}{l|r}
\hline - Yes & $80.90 \%$ \\
\hline - No & $12.80 \%$ \\
\hline - Abstain & $6.40 \%$ \\
\hline
\end{tabular}

Mammaprint in LN+ (based on MINDACT)

Mammaprint low in women of age $<50$ years and 1-2 positive $L N$ may be used to recommend against the indication for adjuvant chemotherapy:

\begin{tabular}{|l|r|}
\hline - Yes & $78.70 \%$ \\
\hline - No & $19.10 \%$ \\
\hline - Abstain & $2.10 \%$ \\
\hline
\end{tabular}

atezolizumab, compared to monotherapy with nab-paclitaxel [50]. In the case of patients with early breast cancer, therapy with chemotherapy (nab-paclitaxel followed by epirubicin + cyclophosphamide) was compared in a phase II study with 174 patients to this chemotherapy + durvalumab. The study demonstrated an increase in pCR from $44.2 \%$ with chemotherapy to $53.4 \%$ with chemotherapy + durvalumab. Given the small number of cases, this difference was not statistically significant, however [51]. Additional therapeutic data from immunotherapies are currently not yet known in the case of early breast cancer. The situation is different with regard to the knowledge gained on tumour-infiltrating lymphocytes (TILs). In a large pooled analysis, it could be shown that TNBC and HER2 patients with high TIL values have a higher response rate to conventional, neoadjuvant chemotherapy and are also associated with a better outcome. In the case of HER2-negative, hormone-receptor-positive patients, this connection is still controversial [52]. In other studies as well, the connection between TILs with the response to neoadjuvant chemotherapy was able to be shown [5355]. In some studies in the adjuvant therapy situation, a prognostic effect was likewise able to be shown [56].

- Table 4 summarises the assessments of the StGP with regard to an integration of TIL determinations and PD-L1 determination in the case of TNBC patients in routine clinical practice. In these votes, it is interesting to note that $66 \%$ of the panel members were of the opinion that TILs should be measured in routine clinical practice, however in the following questions, the vast majority clearly rejected a clinical benefit in routine practice.

\section{Adjuvant Endocrine Therapy - Optimisation Still Underway}

While there is no doubt that all patients without contraindications and with a response to antiendocrine therapy should receive such therapy, several questions are still being discussed.
- Table 4 Votes on immunological-pathological diagnostic measures in TNBC. There were 53 voting experts; the number of those who did not vote is not known.)

\section{Pathology: TNBC only}

TILs should routinely be characterized and reported according to consensus criteria:

\begin{tabular}{|l|l|}
\hline - Yes & $66 \%$ \\
\hline - No & $34 \%$ \\
\hline
\end{tabular}

- Abstain $0 \%$

TILs should be characterized because tumours with high TILs do not need chemotherapy?

\begin{tabular}{|l|c|}
\hline - Yes & $6.10 \%$ \\
\hline - No & $89.80 \%$ \\
\hline - Abstain & $4.10 \%$ \\
\hline Do you obtain TILs in your daily practice? & \\
\hline - Yes & $25.50 \%$ \\
\hline - No & $70.20 \%$ \\
\hline - Abstain & $4.30 \%$ \\
\hline $\begin{array}{l}\text { TILs should be characterized because tumours } \\
\text { with high TILs may need less chemotherapy? }\end{array}$ \\
\hline - Yes & $11.40 \%$ \\
\hline - No & $79.50 \%$ \\
\hline - Abstain & $9.10 \%$ \\
\hline Tumour PDL1 expression should routinely be reported: & \\
\hline - Yes & $20.80 \%$ \\
\hline - No & $79.20 \%$ \\
\hline - Abstain & $0 \%$ \\
\hline $\begin{array}{l}\text { Immune cell PDL1 expression should routinely } \\
\text { be reported: }\end{array}$ & \\
\hline - Yes & $8.50 \%$ \\
\hline - No & $91.50 \%$ \\
\hline - Abstain & $0 \%$ \\
\hline
\end{tabular}

For nearly two decades now, attention has been paid to the question of the cut-off of positively stained cells in immunohistochemistry [57-63]. This also appears to still be a question amongst clinicians ( $\bullet$ Table 5 ).

Another important and frequently discussed subject area is the implementation of optimal antiendocrine therapy in patients in premenopause. In the SOFT and TEXT studies, it was able to be shown that ovarian function suppression (OFS) demonstrated an advantage for disease-free survival when this was combined with therapy with tamoxifen or the aromatase inhibitor exemestane [64]. Patients with exemestane and OFS or tamoxifen and OFS had better disease-free survival than patients with tamoxifen monotherapy. In a comparison of tamoxifen + OFS and exemestane + OFS, it was also seen that therapy with exemestane + OFS demonstrated better disease-free survival. For a better understanding of the data to which these data refer, see $\mathbf{- F i g . ~} \mathbf{2}$. The results for overall survival were not significant in all comparisons and in all subgroups. It should also be noted that the adverse effects on OFS were higher than in the case of monotherapy with 


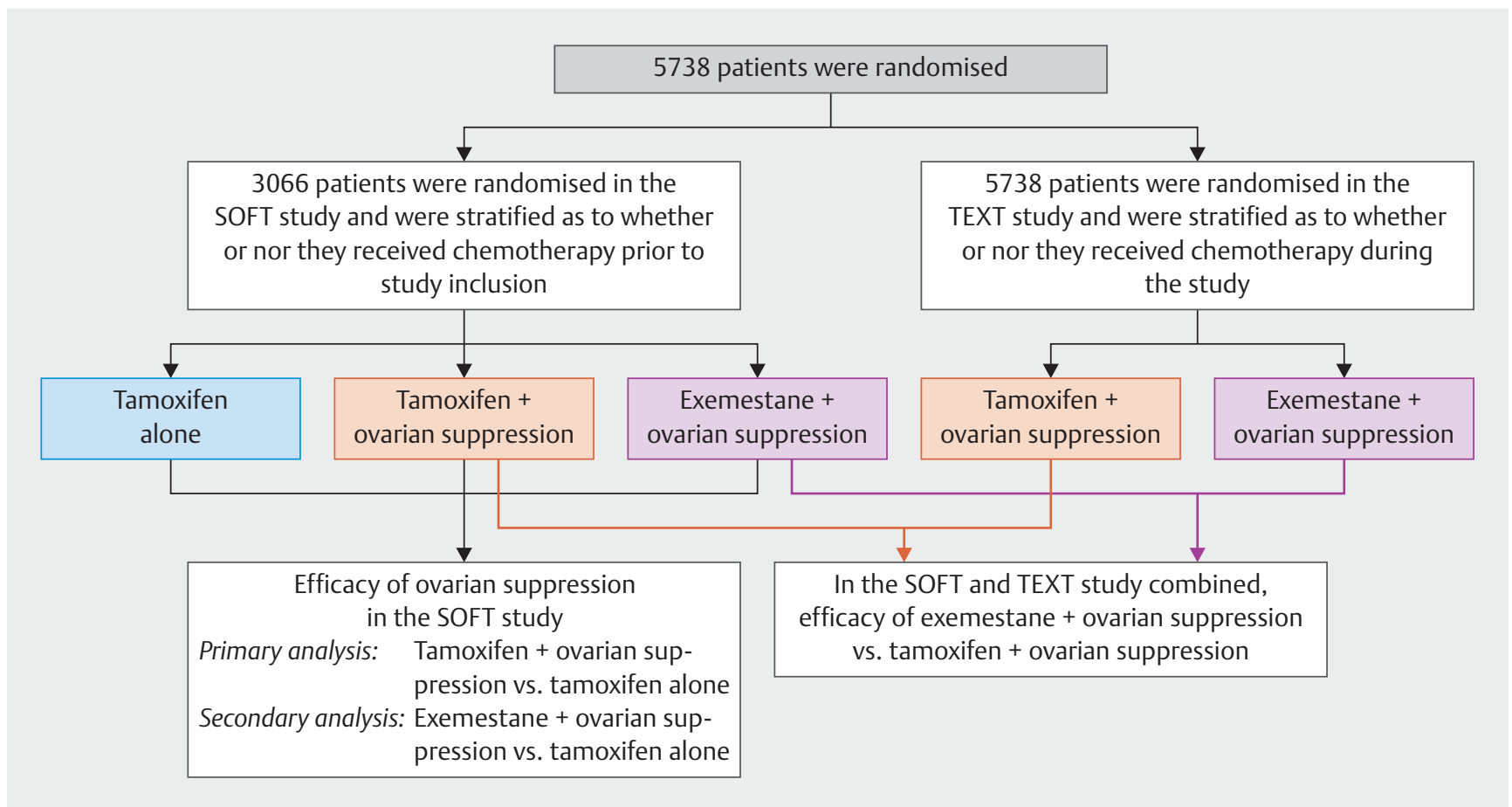

- Fig. 2 Design of the analysis of the SOFT and TEXT studies (according to [64]).

tamoxifen. In view of this, the StGP voted on a series of questions dealing with the issue of which patients should receive OFS and for how long ( $\triangleright$ Table 5). While there was no consensus for some questions, it can be relatively clearly induced from the responses that the panel favours the use of OFS in patients under age 35 who have received chemotherapy.

With regard to the antiendocrine treatment of postmenopausal patients, aromatase inhibitors had already become established more than 10 years ago in various therapies containing an aromatase inhibitor. These therapeutic concepts contained the administration of aromatase inhibitors alone or the start of therapy with tamoxifen and then a switch to an aromatase inhibitor. This gives rise to questions relating to the duration of therapy and whether and for how long a sequence of tamoxifen and aromatase inhibitors can be used ( $\triangleright$ Table 5 ). What is particularly interesting about the results is the fact that the panel bases the decision for expanded therapy significantly on tumour stages and, for example, does not recommend any expanded therapy in stage I even after 5 years of tamoxifen.

\section{Chemotherapy in Neoadjuvant, Adjuvant and Post-Neoadjuvant Situations}

While the introduction of chemotherapy in the treatment of breast cancer as well as the introduction of anthracyclines and taxanes has primarily taken place via classical and, to some extent, very large adjuvant studies, further insights have been able to be gained in recent years, particularly through the combination of knowledge regarding the response to therapy in the neoadjuvant situation and its effects on the prognosis $[44,46]$, regarding the patients in whom chemotherapy leads to a response to chemotherapy and in whom this affects the prognosis. Particularly in the case of patients with TNBC- or HER2-positive carcinoma, a clear connection was able to be established here $[44,46]$.

Some questions which are currently being discussed are the use of anthracyclines, the use of platinum derivatives, the type of chemotherapy (standard dose vs. dose-dense dosing) and the chemotherapy combination partners within the scope of antiHER2 therapies.

In a large randomised study, it was shown that in the case of adjuvant therapy with trastuzumab, therapy with an anthracycline can be avoided if a platinum-based chemotherapy is administered instead [65]. The benefit of avoiding anthracyclines is a reduction in their long-term cardiac effects. In HER2-negative patients as well, it has been hypothesised that chemotherapy containing anthracyclines can be avoided because it is known that a TOP2A amplification is not present in patients with a lack of HER2 amplification [66-68]. TOP2A is in turn one of the main points of attack of chemotherapy containing anthracyclines. In fact, two German studies were able to confirm that anthracycline can be avoided in HER2-negative patients $[69,70]$.

In the case of chemotherapies with dose-dense administration, the data in recent years have also become concentrated such that it can be estimated for most groups of patients whether and how they benefit from dose-dense chemotherapy [71]. The data are documented via a number of studies and meta-analyses performed [72]. The experts of the StGP voted on these questions as well.

Also of interest were the opinions on the use of platinumbased chemotherapy in triple-negative patients. The background 
- Table 5 Votes (excerpt) in connection with adjuvant antihormonal therapy. There were 53 voting experts; the number of those who did not vote is not known.)

\section{Endocrine therapy}

Ideal cut off to prescribe endocrine therapy:

\begin{tabular}{|l|c|}
\hline - $E R>1 \%$ & $30.60 \%$ \\
\hline " $E R>5 \%$ & $4.10 \%$ \\
\hline - $E R>10 \%$ & $38.80 \%$ \\
\hline - The answer is not clear & $24.50 \%$ \\
\hline - Abstain & $2 \%$ \\
\hline $\begin{array}{l}\text { Endocrine therapy - Premenopausal: selection } \\
\text { factors }\end{array}$ \\
\hline
\end{tabular}

Clinico-pathological indications for ovarian function suppression (OFS) are:

Those given chemotherapy:

- Yes

$68.10 \%$

- No

$25.50 \%$

- Abstain

$6.40 \%$

Clinico-pathological indications by itself for ovarian

function suppression (OFS) include:

\begin{tabular}{|l|l|}
\hline Age $\leq 35$ years & \\
\hline - Yes & $84.80 \%$ \\
\hline - No & $8.70 \%$ \\
\hline - Abstain & $6.50 \%$ \\
\hline Moderate risk not getting chemotherapy & \\
\hline - Yes & $45.80 \%$ \\
\hline - No & $41.70 \%$ \\
\hline - Abstain & $12.50 \%$ \\
\hline Premenopausal E2 level after (neo)adjuvant & \\
\hline chemotherapy & \\
\hline - Yes & not \\
\hline - No & available \\
\hline - Abstain & not \\
\hline Involvement of how many nodes? & available \\
\hline - 1+ & not \\
\hline - 2-3+ & available \\
\hline - $4+$ & $37.80 \%$ \\
\hline - Abstain & $13.30 \%$ \\
\hline Adverse result of multi-gene test & $17.80 \%$ \\
\hline - Yes & $31.10 \%$ \\
\hline - No & \\
\hline - Abstain & $17 \%$ \\
\hline - Yes2+ status & $59.60 \%$ \\
\hline
\end{tabular}

- Table 5 Votes (excerpt) in connection with adjuvant antihormonal therapy. There were 53 voting experts; the number of those who did not vote is not known.) (Continued)

\section{Endocrine therapy - Duration (postmenopausal)} beyond 5 years

It is understood that 5 years of endocrine therapy is a historic standard, and that only patients who have tolerated such treatment reasonably well would discuss longer durations of therapy. Would you recommend extended therapy for:

\begin{tabular}{|l|r|}
\hline Stage 1, after 5 years tamoxifen? & $25.50 \%$ \\
\hline - Yes & $72.30 \%$ \\
\hline - No & $2.10 \%$ \\
\hline - Abstain & \\
\hline Stage 1, after 5 years of an Al? & $19.60 \%$ \\
\hline - Yes & $78.30 \%$ \\
\hline - No & $2.20 \%$ \\
\hline - Abstain & \\
\hline Stage 2, node-negative, after 5 years of tamoxifen?
\end{tabular}

- Yes

$68.10 \%$

- No

$27.70 \%$

- Abstain

$4.30 \%$

Stage 2, node-negative, after 5 years of an Al?

- Yes

$34.70 \%$

- No

$59.20 \%$

- Abstain

$6.10 \%$

Stage 2, node-positive, after 5 years of tamoxifen?

\begin{tabular}{|l|c|}
\hline - Yes & $97.90 \%$ \\
\hline - No & $2.10 \%$ \\
\hline - Abstain & $0 \%$ \\
\hline
\end{tabular}

Stage 2, node-positive, after 5 years of an Al?

$\begin{array}{ll}\text { - Yes } & 81.20 \%\end{array}$

- No

$12.50 \%$

- Abstain

$6.20 \%$

Patients receiving extended endocrine therapy should aim for a total treatment duration of:

\begin{tabular}{l|r}
\hline - 10 years & $58.50 \%$ \\
\hline - $7-8$ years & $31.70 \%$ \\
\hline - Abstain & $9.80 \%$ \\
\hline
\end{tabular}

Patients at very high risk (e.g. 10 or more positive nodes) should receive endocrine therapy beyond 10 years

- Yes

$14.60 \%$

- No

$22.90 \%$

- Case by case

$60.40 \%$

- Abstain

$2.10 \%$ 
is that it is assumed that in patients with a triple-negative tumour, DNA repair mechanisms are more frequently disrupted and therefore platinum-based chemotherapies work better. In the neoadjuvant situation, there are solid data which show that platinumbased chemotherapies increase the PCR rate, however this happens at the cost of more frequent and more severe haematological toxicities [73]. With regard to the prognosis, the studies were not able to establish such a clear connection [73]. The votes regarding chemotherapy are shown in $\mathbf{T}$ Table $\mathbf{6}$. An interesting aspect shown by the international composition of the panel cannot be seen from the voting results, however this was very clear during the discussion. While in Germany the indication for neoadjuvant chemotherapy is largely based on the tumour biology, the head of the panel, Eric Winer, clarified that in the USA, only a minority of patients in stage I are treated neoadjuvantly and in these cases, adjuvant chemotherapy is generally preferred.

\section{The Post-Neoadjuvant Situation}

Particularly in Germany, neoadjuvant chemotherapy has established itself for most patients with an indication for chemotherapy. Only recently, a meta-analysis confirmed that neoadjuvant chemotherapy prior to surgery is as certain with regard to the oncological outcome as adjuvant chemotherapy following surgery [74]. It is clear that patients after a lack of PCR have a significantly worse prognosis than patients who achieved PCR $[44,46]$ or than the average of patients who received adjuvant chemotherapy [74]. Attempts have been made for some time to establish additional therapies for these patients. In an Asian study, the diseasefree survival and overall survival were able to be improved for HER2-negative patients if post-neoadjuvant capecitabine was given additionally after the surgery, after a lack of pCR following neo-

- Table 6 Votes (excerpt) regarding (neo)adjuvant chemotherapy. There were 53 voting experts; the number of those who did not vote is not known.)

\section{Preferred chemotherapy regimens in ER+ breast} cancer in $\mathrm{N}$ -

The preferred chemo-regimen should be:

- Anthracyclines, alkylators and taxanes

$31.20 \%$

- Alkylators and taxanes

$54.20 \%$

- Alkylators only

$4.20 \%$

- Abstain

$10.40 \%$

Chemotherapy in TNBC: anthracyclines

In women with stage 1 TNBC, the preferred

chemotherapy regimen should be:

\begin{tabular}{|l|c|}
\hline - Anthracyclines, alkylators and taxanes & $77.60 \%$ \\
\hline - Alkylators and taxanes & $16.30 \%$ \\
\hline - Alkylators only & $0 \%$ \\
\hline - Abstain & $6.10 \%$ \\
\hline
\end{tabular}

- Table 6 Votes (excerpt) regarding (neo)adjuvant chemotherapy. There were 53 voting experts; the number of those who did not vote is not known.) (Continued)

In women with stage 1 TNBC, the preferred chemotherapy regimen should be (in PT1a/b):

- Anthracyclines, alkylators and taxanes $30.40 \%$

- Alkylators and taxanes

$52.20 \%$

- Alkylators only

$4.30 \%$

- Abstain $13 \%$

Women with stage 2 or 3 TNBC should receive which chemotherapy regimen:

\begin{tabular}{|l|c|}
\hline - Anthracyclines, alkylators and taxanes & $93.30 \%$ \\
\hline - Alkylators and taxanes & $2.20 \%$ \\
\hline - Alkylators only & $0 \%$ \\
\hline - Abstain & $4.40 \%$ \\
\hline
\end{tabular}

TNBC chemotherapy: neoadjuvant platinum

Should a platinum-based regimen be recommended

In addition to $\mathrm{T} / \mathrm{C} / \mathrm{A}$ based regimens

\begin{tabular}{l|r}
\hline - Yes & $34.80 \%$ \\
\hline - No & $56.50 \%$ \\
\hline - Abstain & $8.70 \%$ \\
\hline
\end{tabular}

In patients with known BRCA mutation

\begin{tabular}{ll} 
- Yes & $67.30 \%$ \\
\hline
\end{tabular}

- No

$26.50 \%$

- Abstain

$6.10 \%$

Chemotherapy in TNBC; tumour less than $6 \mathrm{~mm}$ N0

Should women with unifocal PT1a pNO receive chemo?

- Always

$0 \%$

- Sometimes

$65.30 \%$

- Never

$34.70 \%$

- Abstain

$0 \%$

Optimal chemotherapy schedule

When giving adjuvant/neoadjuvant chemotherapy with anthracycline and taxanes, the preferred schedule is:

\begin{tabular}{l|c}
\hline - Standard & $31.70 \%$ \\
\hline - Dose-dense & $61 \%$ \\
\hline - Abstain & $7.30 \%$ \\
\hline HER2+ breast cancer & \\
\hline $\begin{array}{l}\text { It is understood that standard management for HER2+ } \\
\text { breast cancer includes chemotherapy and trastuzumab, } \\
\text { including patients with stage } 1 \text { tumours. Do the large } \\
\text { majority of patients with HER2 positive node-negative } \\
\text { disease require anti-HER2 therapy: }\end{array}$ \\
\hline \begin{tabular}{l} 
With T1a disease? \\
\hline - Yes
\end{tabular} \\
\hline - No & \\
\hline - Abstain & $42.60 \%$ \\
\hline
\end{tabular}

Continued next page 
- Table 6 Votes (excerpt) regarding (neo)adjuvant chemotherapy. There were 53 voting experts; the number of those who did not vote is not known.) (Continued)

Does ER status affect any of these thresholds?

\begin{tabular}{|l|c|}
\hline - Yes & $27.70 \%$ \\
\hline - No & $61.70 \%$ \\
\hline - Abstain & $10.60 \%$ \\
\hline The preferred regimen for stage 1 adjuvant, HER2+ is: & \\
\hline - TH & $73.50 \%$ \\
\hline - THP & $4.10 \%$ \\
\hline - TCHP & $2 \%$ \\
\hline - AC/TH(P) & $12.20 \%$ \\
\hline - Abstain & $8.20 \%$ \\
\hline HER2+ tumours: stage 2 (N+) or 3 & \\
\hline The preferred adjuvant or neoadjuvant approach for & \\
\hline stage 2 (N+) or stage 3, HER2 positive breast cancer is: & \\
\hline - Docetaxel carboplatin trastuzumab pertuzumab & $14.30 \%$ \\
\hline - AC/EC $\rightarrow$ taxane trastuzumab pertuzumab & $75.50 \%$ \\
\hline - Docetaxel carboplatin trastuzumab & $0 \%$ \\
\hline - AC/EC $\rightarrow$ taxane trastuzumab & $4.10 \%$ \\
\hline - Abstain & $6.10 \%$ \\
\hline HER2+/ER+ tumours: stage 1 & \\
\hline
\end{tabular}

Pertuzumab is a standard when using trastuzumab with indication for neoadjuvant therapy:

\begin{tabular}{|l|l|}
\hline " Yes & $33.30 \%$ \\
\hline " No & $52.10 \%$ \\
\hline " Abstain & $14.60 \%$ \\
\hline
\end{tabular}

Pertuzumab should be added in:

\begin{tabular}{l|r}
\hline - All cases & $12.80 \%$ \\
\hline - ER+only & $2.10 \%$ \\
\hline - ER-only & $25.50 \%$ \\
\hline - None & $48.90 \%$ \\
\hline - Abstain & $10.60 \%$ \\
\hline
\end{tabular}

HER2+ preferred approaches stage $2(\mathrm{~N}+)$ or 3

Pertuzumab should be added in:

\begin{tabular}{|l|c|}
\hline - All cases & $76.60 \%$ \\
\hline - ER+only & $2.10 \%$ \\
\hline . ER- only & $19.10 \%$ \\
\hline " None & $0 \%$ \\
\hline " Abstain & $2.10 \%$ \\
\hline
\end{tabular}

adjuvant chemotherapy [75]. Similarly, it was shown in the case of HER2-positive patients that if no pCR could be achieved following neoadjuvant anti-HER2 therapy with chemotherapy, therapy with T-DM1 is more effective than standard treatment with trastuzumab [76]. Additional post-neoadjuvant studies have currently not yet ended, such as the PenelopeB study [77]. The voting results regarding this interesting therapeutic situation can be found in $>$ Table $\mathbf{7}$ and demonstrate a high level of acceptance for postneoadjuvant concepts.
- Table 7 Votes regarding post-neoadjuvant therapy. There were 53 voting experts; the number of those who did not vote is not known.)

Management of residual disease after neoadjuvant therapy: TNBC

If there is residual cancer in axillary $L N$ or breast $(\geq 1 \mathrm{~cm}$ residual cancer and/or $\mathrm{LN}+$ ) following neoadjuvant sequential AC $\rightarrow$ T chemotherapy for TNBC, your preferred systemic therapy is:

- No further therapy

- Capecitabine $83.30 \%$

- Platinum based $2.10 \%$

- Classical CMF $4.20 \%$

- Abstain $4.20 \%$

If there is residual cancer in breast only $(<1.0 \mathrm{~cm}$ residual cancer $\mathrm{LN}^{-}$) following neoadjuvant sequential AC $\rightarrow$ T chemotherapy for TNBC, your preferred systemic therapy is:

- No further therapy $38.80 \%$

- Capecitabine $51 \%$

- Platinum based $2 \%$

- Classical CMF $2 \%$

- Abstain $6.10 \%$

Management of residual disease after neoadjuvant therapy: HER2+

If there is residual cancer in breast and/or axillary LN (no $\mathrm{pCR} /$ near $\mathrm{pCR}$ ) following neoadjuvant $\mathrm{TCH}$ or $\mathrm{AC} / \mathrm{EC} \rightarrow \mathrm{TH}$ (without P), in HER2 + breast cancer, your preferred systemic therapy is:

\begin{tabular}{|l|r|}
\hline - No further therapy & $0 \%$ \\
\hline - H & $0 \%$ \\
\hline - HP & $4.20 \%$ \\
\hline - TDM1 & $91.70 \%$ \\
\hline - Abstain & $4.20 \%$ \\
\hline
\end{tabular}

If there is residual cancer in breast and/or axillary $L N$ $(\geq 1 \mathrm{~cm}$ residual cancer) following neoadjuvant TCHP or $\mathrm{AC} / \mathrm{EC} \rightarrow \mathrm{THP}$, in HER2+ breast cancer, your preferred systemic therapy is:

- No further therapy $0 \%$

- $\mathrm{H} \quad 0 \%$

- HP

$0 \%$

- TDM1 $93.90 \%$

- Abstain $4.10 \%$

\section{Other Fields in the Treatment of the Early Breast Cancer Patient}

Regardless of the optimisation of therapy, additional important fields in the treatment of patients with early breast cancer have been discussed. These are no less important than those discussed here in more detail. For a better overview, all voting results are included in the appendix (supplementary Table S1). It shows results 
from the votes in areas such as pregnancy following breast cancer, preservation of fertility, use of antiresorptive therapies (bisphosphonates, denosumab), nutrition and physical activity as well as several aspects in the treatment of ductal carcinoma in situ (DCIS). It is important that these aspects remain in the focus of the patients and also the attending physicians. Overtreatment in the case of DCIS is an area here which is as equally important as the concerns of patients who survive breast cancer, such that life after the disease can be ensured with a quality of life which is comparable to that of patients who never had breast cancer.

\section{Outlook}

While this year's vote by the StGP showed that some of the questions from recent decades are relatively clear today, a few other topics still led to controversial votes. All of the voting results are available in supplementary Table S1. However today, the format of the St. Gallen panel, in view of evidence-based guidelines such as the S3 guideline and recommendations such as those of the AGO "Mamma" organ committee, has a different meaning than at the time of its initiation 32 years ago. While in the initial years, the votes in St. Gallen were like a guideline since there was a lack of other guidance, they nowadays rather reflect an international atmosphere which can provide help in clinical assessments and decisions, particularly in situations in which there are no specific recommendations.

The next gains in knowledge are expected to be in relation to substances which have already shown significant efficacy in the metastatic situation. Large, randomised studies in the (neo)adjuvant therapy situation have been started for PARP inhibition, CDK4/6 inhibitors and checkpoint inhibitors. Some of them have already completed recruitment and thus corresponding results are expected in the near future.

\section{Acknowledgements}

This work was developed in part as a result of grants from onkowissen.de and Hexal. The authors alone are responsible for the content of the manuscript. None of the companies played a role in the drafting of this manuscript.

\section{Conflict of Interest}

A.D.H. received speaker and consultancy honoraria from AstraZeneca, Genomic Health, Roche, Novartis, Celgene, Lilly, MSD, Eisai, Teva, Tesaro, Daiichi-Sankyo, Hexal and Pfizer. F. O. received speaker and consultancy honoraria from Amgen, AstraZeneca, Bayer, BMS, BoehringerIngelheim, Chugai, Celgene, Cellex, Eisai, Gilead, Hexal, Ipsen, JanssenCilag, Merck, MSD, Novartis, Riemser, Roche, Tesaro, Teva. F.-A.T. received honoraria from AstraZeneca, Genomic Health and Novartis. H.-C.K. received honoraria from Carl Zeiss meditec, Teva, Theraclion, Novartis, Amgen, AstraZeneca, Pfizer, Janssen-Cilag, GSK, LIV Pharma, Roche and Genomic Health, travel support from Tesaro and Daiichi Sankyo and owns stock of Theraclion. P. A. F. reports grants from Novartis, Cepheid and Biontech, personal fees from Novartis, Roche, Pfizer, Celgene, Daiichi-Sankyo, Teva, AstraZeneca, Merck Sharp \& Dohme, Myelo Therapeutics, Macrogenics, Eisai, and Puma H.T. received honoraria from Novartis, Roche, Celgene, Teva, Pfizer and travel support from Roche, Celgene and Pfizer. J. E. received honoraria from AstraZeneca, Roche, Celgene, Novartis, Lilly, Pfizer, Pierre Fabre, Teva and travel sup- port from Celgene, Pfizer, Teva and Pierre Fabre. M. P. L. has participated on advisory boards for AstraZeneca, MSD, Novartis, Pfizer, Eisai, Genomic Health, Tesaro, Grünethal and Roche and has received honoraria for lectures from MSD, Lilly, Roche, Novartis, Pfizer, Genomic Health, AstraZeneca, medac and Eisai. V. M. received speaker honoraria from Amgen, AstraZeneca, Celgene, Daiichi-Sankyo, Eisai, Pfizer, Novartis, Roche, Teva, Janssen-Cilag and consultancy honoraria from Genomic Health, Hexal, Roche, Pierre Fabre, Amgen, Novartis, MSD, DaiichiSankyo and Eisai, Lilly, Tesaro and Nektar. E. B. received honoraria from Novartis, Celgene, Riemser, Pfizer, Hexal, Amgen, and onkowissen.de for consulting, clinical research management or medical education activities. A. S. received honoraria from Roche, Celgene, AstraZeneca, Novartis, Pfizer, Zuckschwerdt Verlag GmbH, Georg Thieme Verlag, Aurikamed $\mathrm{GmbH}$, MCl Deutschland $\mathrm{GmbH}$, bsh medical communications $\mathrm{GmbH}$ and promedicis $\mathrm{GmbH}$. W. J. received honoraria and research grants from Novartis, Roche, Pfizer, Lilly, AstraZeneca, Chugai, Sanofi, Daichi, Tesaro. F. S. participated on advisory boards for Novartis, Lilly, Amgen and Roche and received honoraria for lectures from Roche, AstraZeneca, MSD, Novartis and Pfizer. A. W. participated on advisory boards for Novartis, Lilly, Amgen, Pfizer, Roche, Tesaro, Eisai and received honoraria for lectures from Novartis, Pfizer, Aurikamed, Roche and Celgene. D. L. received honorarium from Amgen, AstraZeneca, Celgene, Daiichi Sankyo, Lilly, Loreal, MSD, Novartis, Pfizer, Tesaro, Teva. T. N. F. has participated on advisory boards for Amgen, Daichi Sankyo, Novartis, Pfizer, and Roche and has received honoraria for lectures from Amgen, Celgene, Daichi Sankyo, Roche, Novartis and Pfizer. J.H. received honoraria from Novartis, Roche, Celgene, Teva, Pfizer and travel support from Roche, Celgene and Pfizer. M. W. received speaker honoraria from AstraZeneca, Celgene and Novartis. S. Y.B. received honoraria from Novartis, Roche and AstraZeneca. All remaining authors (C.P., A.T.) declare that they have no conflict of interest.

\section{References}

[1] Wockel A, Festl J, Stuber T et al. Interdisciplinary Screening, Diagnosis, Therapy and Follow-up of Breast Cancer. Guideline of the DGGG and the DKG (S3-Level, AWMF Registry Number 032/045OL, December 2017) - Part 1 with Recommendations for the Screening, Diagnosis and Therapy of Breast Cancer. Geburtsh Frauenheilk 2018; 78: 927-948

[2] Wockel A, Festl J, Stuber T et al. Interdisciplinary Screening, Diagnosis, Therapy and Follow-up of Breast Cancer. Guideline of the DGGG and the DKG (S3-Level, AWMF Registry Number 032/045OL, December 2017) - Part 2 with Recommendations for the Therapy of Primary, Recurrent and Advanced Breast Cancer. Geburtsh Frauenheilk 2018; 78: 1056-1088

[3] Kreienberg R, Wockel A, Wischnewsky M. Highly significant improvement in guideline adherence, relapse-free and overall survival in breast cancer patients when treated at certified breast cancer centres: An evaluation of 8323 patients. Breast 2018; 40: 54-59

[4] Brennan M, Gass P, Haberle L et al. The effect of participation in neoadjuvant clinical trials on outcomes in patients with early breast cancer. Breast Cancer Res Treat 2018. doi:10.1007/s10549-018-4829-4

[5] Brennan MB, Gass P, Häberle L et al. The effect of participation in neoadjuvant clinical trials on outcomes in patients with early breast cancer. Breast Cancer Res Treat 2018; 171: 747-758

[6] Schwentner L, Van Ewijk R, Kurzeder C et al. Participation in adjuvant clinical breast cancer trials: does study participation improve survival compared to guideline adherent adjuvant treatment? A retrospective multi-centre cohort study of 9,433 patients. Eur J Cancer 2013; 49: 553-563

[7] Beckmann MW, Brucker C, Hanf V et al. Quality assured health care in certified breast centers and improvement of the prognosis of breast cancer patients. Onkologie 2011; 34: 362-367 
[8] Kommission Mamma der Arbeitsgemeinschaft Gynäkologische Onkologie e.V. in der Deutschen Gesellschaft für Gynäkologie und Geburtshilfe e.V. sowie in der Deutschen Krebsgesellschaft e.V. Diagnostik und Therapiefrüher und fortgeschrittener Mammakarzinome. 2019. https:// www.ago-online.de/de/infothek-fuer-aerzte/leitlinienempfehlungen/ mamma/; last access: 27.03.2019

[9] Couch F], Hart SN, Sharma P et al. Inherited mutations in 17 breast cancer susceptibility genes among a large triple-negative breast cancer cohort unselected for family history of breast cancer. J Clin Oncol 2015; 33 : 304-311

[10] Couch F], Shimelis H, Hu C et al. Associations Between Cancer Predisposition Testing Panel Genes and Breast Cancer. JAMA Oncol 2017; 3: 1190-1196

[11] Mavaddat N, Michailidou K, Dennis J et al. Polygenic Risk Scores for Prediction of Breast Cancer and Breast Cancer Subtypes. Am J Hum Genet 2018. doi:10.1016/j.ajhg.2018.11.002

[12] Shimelis H, LaDuca H, Hu C et al. Triple-Negative Breast Cancer Risk Genes Identified by Multigene Hereditary Cancer Panel Testing. J Natl Cancer Inst 2018. doi:10.1093/jnci/djy106

[13] Milne RL, Kuchenbaecker KB, Michailidou K et al. Identification of ten variants associated with risk of estrogen-receptor-negative breast cancer. Nat Genet 2017; 49: 1767-1778

[14] Michailidou K, Lindstrom S, Dennis J et al. Association analysis identifies 65 new breast cancer risk loci. Nature 2017; 551: 92-94

[15] Michailidou K, Beesley ], Lindstrom S et al. Genome-wide association analysis of more than 120,000 individuals identifies 15 new susceptibility loci for breast cancer. Nat Genet 2015; 47: 373-380

[16] Michailidou K, Hall P, Gonzalez-Neira A et al. Large-scale genotyping identifies 41 new loci associated with breast cancer risk. Nat Genet 2013; 45: 353-361, 361e1-361e2

[17] Ghoussaini M, Fletcher O, Michailidou K et al. Genome-wide association analysis identifies three new breast cancer susceptibility loci. Nat Genet 2012; 44: 312-318

[18] Varghese JS, Easton DF. Genome-wide association studies in common cancers-what have we learnt? Curr Opin Genet Dev 2010; 20: 201-209

[19] Wunderle M, Gass P, Haberle L et al. BRCA mutations and their influence on pathological complete response and prognosis in a clinical cohort of neoadjuvantly treated breast cancer patients. Breast Cancer Res Treat 2018; 171: 85-94

[20] Haberle L, Hein A, Rubner M et al. Predicting Triple-Negative Breast Cancer Subtype Using Multiple Single Nucleotide Polymorphisms for Breast Cancer Risk and Several Variable Selection Methods. Geburtsh Frauenheilk 2017; 77: 667-678

[21] Vachon CM, Pankratz VS, Scott CG et al. The contributions of breast density and common genetic variation to breast cancer risk. J Natl Cancer Inst 2015; 107: pii: dju397

[22] Mavaddat N, Pharoah PD, Michailidou K et al. Prediction of breast cancer risk based on profiling with common genetic variants. J Natl Cancer Inst 2015; 107: pii: djv036

[23] Purrington KS, Slager S, Eccles D et al. Genome-wide association study identifies 25 known breast cancer susceptibility loci as risk factors for triple-negative breast cancer. Carcinogenesis 2014; 35: 1012-1019

[24] Vachon CM, Scott CG, Fasching PA et al. Common breast cancer susceptibility variants in LSP1 and RAD51L1 are associated with mammographic density measures that predict breast cancer risk. Cancer Epidemiol Biomarkers Prev 2012; 21: 1156-1166

[25] Stevens KN, Fredericksen Z, Vachon CM et al. 19p13.1 is a triple-negative-specific breast cancer susceptibility locus. Cancer Res 2012; 72: 1795-1803

[26] Stevens KN, Vachon CM, Lee AM et al. Common breast cancer susceptibility loci are associated with triple-negative breast cancer. Cancer Res 2011; 71: 6240-6249
[27] Litton JK, Rugo HS, Ettl ] et al. Talazoparib in Patients with Advanced Breast Cancer and a Germline BRCA Mutation. N Engl J Med 2018; 379: 753-763

[28] Robson M, Im SA, Senkus E et al. Olaparib for Metastatic Breast Cancer in Patients with a Germline BRCA Mutation. N Engl J Med 2017; 377: $523-$ 533

[29] Hartkopf AD, Brucker SY, Taran FA et al. International pooled analysis of the prognostic impact of disseminated tumor cells from the bone marrow in early breast cancer: Results from the PADDY study. San Antonio Breast Cancer Symposium 2018; 2018: Abstract GS5-07

[30] Hahnen E, Lederer B, Hauke J et al. Germline Mutation Status, Pathological Complete Response, and Disease-Free Survival in Triple-Negative Breast Cancer: Secondary Analysis of the GeparSixto Randomized Clinical Trial. JAMA Oncol 2017; 3: 1378-1385

[31] Copson ER, Maishman TC, Tapper W] et al. Germline BRCA mutation and outcome in young-onset breast cancer ( $\mathrm{POSH})$ : a prospective cohort study. Lancet Oncol 2018. doi:10.1016/S1470-2045(17)30891-4

[32] Halsted WS. I. The Results of Operations for the Cure of Cancer of the Breast Performed at the Johns Hopkins Hospital from June, 1889, to January, 1894. Ann Surg 1894; 20: 497-555

[33] Patey DH. A review of 146 cases of carcinoma of the breast operated on between 1930 and 1943. Br J Cancer 1967; 21: 260-269

[34] Fisher B, Anderson S, Bryant J et al. Twenty-year follow-up of a randomized trial comparing total mastectomy, lumpectomy, and lumpectomy plus irradiation for the treatment of invasive breast cancer. N Engl ] Med 2002; 347: 1233-1241

[35] Veronesi U, Cascinelli N, Mariani L et al. Twenty-year follow-up of a randomized study comparing breast-conserving surgery with radical mastectomy for early breast cancer. N Engl J Med 2002; 347: 1227-1232

[36] van Roozendaal LM, Vane MLG, van Dalen T et al. Clinically node negative breast cancer patients undergoing breast conserving therapy, sentinel lymph node procedure versus follow-up: a Dutch randomized controlled multicentre trial (BOOG 2013-08). BMC Cancer 2017; 17: 459

[37] Reimer T, Stachs A, Nekljudova V et al. Restricted Axillary Staging in Clinically and Sonographically Node-Negative Early Invasive Breast Cancer (c/iT1-2) in the Context of Breast Conserving Therapy: First Results Following Commencement of the Intergroup-Sentinel-Mamma (INSEMA) Trial. Geburtsh Frauenheilk 2017; 77: 149-157

[38] Gentilini O, Veronesi U. Abandoning sentinel lymph node biopsy in early breast cancer? A new trial in progress at the European Institute of Oncology of Milan (SOUND: Sentinel node vs. Observation after axillary UltraSouND). Breast 2012; 21: 678-681

[39] Donker M, van Tienhoven G, Straver ME et al. Radiotherapy or surgery of the axilla after a positive sentinel node in breast cancer (EORTC 1098122023 AMAROS): a randomised, multicentre, open-label, phase 3 noninferiority trial. Lancet Oncol 2014; 15: 1303-1310

[40] Galimberti V, Cole BF, Zurrida S et al. Axillary dissection versus no axillary dissection in patients with sentinel-node micrometastases (IBCSG 2301): a phase 3 randomised controlled trial. Lancet Oncol 2013; 14: 297-305

[41] Galimberti V, Cole BF, Viale G et al. Axillary dissection versus no axillary dissection in patients with breast cancer and sentinel-node micrometastases (IBCSG 23-01): 10-year follow-up of a randomised, controlled phase 3 trial. Lancet Oncol 2018; 19: 1385-1393

[42] Giuliano AE, Ballman KV, McCall L et al. Effect of Axillary Dissection vs. No Axillary Dissection on 10-Year Overall Survival Among Women With Invasive Breast Cancer and Sentinel Node Metastasis: The ACOSOC Z0011 (Alliance) Randomized Clinical Trial. JAMA 2017; 318: 918-926

[43] Giuliano AE, Ballman K, McCall L et al. Locoregional Recurrence After Sentinel Lymph Node Dissection With or Without Axillary Dissection in Patients With Sentinel Lymph Node Metastases: Long-term Follow-up From the American College of Surgeons Oncology Group (Alliance) ACOSOG Z0011 Randomized Trial. Ann Surg 2016; 264: 413-420 
[44] Cortazar P, Zhang L, Untch M et al. Pathological complete response and long-term clinical benefit in breast cancer: the CTNeoBC pooled analysis. Lancet 2014; 384: 164-172

[45] Fasching PA, Heusinger K, Haeberle L et al. Ki67, chemotherapy response, and prognosis in breast cancer patients receiving neoadjuvant treatment. BMC Cancer 2011; 11: 486

[46] von Minckwitz G, Untch M, Blohmer JU et al. Definition and impact of pathologic complete response on prognosis after neoadjuvant chemotherapy in various intrinsic breast cancer subtypes. J Clin Oncol 2012; 30: 1796-1804

[47] Cardoso F, van't Veer LJ, Bogaerts J et al. 70-Gene Signature as an Aid to Treatment Decisions in Early-Stage Breast Cancer. N Engl J Med 2016; 375: 717-729

[48] Sparano JA, Gray RJ, Makower DF et al. Adjuvant Chemotherapy Guided by a 21-Gene Expression Assay in Breast Cancer. N Engl J Med 2018; 379 : 111-121

[49] Kurian AW, Bondarenko I, Jagsi R et al. Recent Trends in Chemotherapy Use and Oncologists' Treatment Recommendations for Early-Stage Breast Cancer. J Natl Cancer Inst 2018; 110: 493-500

[50] Schmid P, Adams S, Rugo HS et al. Atezolizumab and Nab-Paclitaxel in Advanced Triple-Negative Breast Cancer. N Engl J Med 2018; 379: 2108-2121

[51] Loibl S, Untch M, Burchardi N et al. Randomized phase II neoadjuvant study (GeparNuevo) to investigate the addition of durvalumab to a taxane-anthracycline containing chemotherapy in triple negative breast cancer (TNBC). J Clin Oncol 2018; 36 (15_suppl): 104

[52] Denkert C, von Minckwitz G, Darb-Esfahani S et al. Tumour-infiltrating lymphocytes and prognosis in different subtypes of breast cancer: a pooled analysis of 3771 patients treated with neoadjuvant therapy. Lancet Oncol 2018; 19: 40-50

[53] O'Loughlin M, Andreu X, Bianchi S et al. Reproducibility and predictive value of scoring stromal tumour infiltrating lymphocytes in triple-negative breast cancer: a multi-institutional study. Breast Cancer Res Treat 2018; 171: 1-9

[54] Wurfel F, Erber R, Huebner $\mathrm{H}$ et al. TILGen: A Program to Investigate Immune Targets in Breast Cancer Patients - First Results on the Influence of Tumor-Infiltrating Lymphocytes. Breast Care (Basel) 2018; 13: 8-14

[55] Ali HR, Dariush A, Thomas J et al. Lymphocyte density determined by computational pathology validated as a predictor of response to neoadjuvant chemotherapy in breast cancer: secondary analysis of the ARTemis trial. Ann Oncol 2017; 28: 1832-1835

[56] Criscitiello C, Bagnardi V, Pruneri G et al. Prognostic value of tumour-infiltrating lymphocytes in small HER2-positive breast cancer. Eur J Cancer 2017; 87: 164-171

[57] Goldhirsch A, Glick JH, Gelber RD et al. Meeting highlights: International Consensus Panel on the Treatment of Primary Breast Cancer. Seventh International Conference on Adjuvant Therapy of Primary Breast Cancer. J Clin Oncol 2001; 19: 3817-3827

[58] Goldhirsch A, Wood WC, Gelber RD et al. Meeting highlights: updated international expert consensus on the primary therapy of early breast cancer. J Clin Oncol 2003; 21: 3357-3365

[59] Goldhirsch A, Glick JH, Gelber RD et al. Meeting highlights: international expert consensus on the primary therapy of early breast cancer 2005 . Ann Oncol 2005; 16: 1569-1583

[60] Goldhirsch A, Wood WC, Gelber RD et al. Progress and promise: highlights of the international expert consensus on the primary therapy of early breast cancer 2007. Ann Oncol 2007; 18: 1133-1144

[61] Goldhirsch A, Ingle JN, Gelber RD et al. Thresholds for therapies: highlights of the St Gallen International Expert Consensus on the primary therapy of early breast cancer 2009. Ann Oncol 2009; 20: 1319-1329
[62] Goldhirsch A, Wood WC, Coates AS et al. Strategies for subtypes-dealing with the diversity of breast cancer: highlights of the St. Gallen International Expert Consensus on the Primary Therapy of Early Breast Cancer 2011. Ann Oncol 2011; 22: 1736-1747

[63] Goldhirsch A, Winer EP, Coates AS et al. Personalizing the treatment of women with early breast cancer: highlights of the St Gallen International Expert Consensus on the Primary Therapy of Early Breast Cancer 2013. Ann Oncol 2013; 24: 2206-2223

[64] Francis PA, Pagani O, Fleming GF et al. Tailoring Adjuvant Endocrine Therapy for Premenopausal Breast Cancer. N Engl J Med 2018; 379: 122-137

[65] Slamon D, Eiermann W, Robert $\mathrm{N}$ et al. Adjuvant trastuzumab in HER2positive breast cancer. N Engl J Med 2011; 365: 1273-1283

[66] Konecny GE, Pauletti G, Untch M et al. Association between HER2, TOP2A, and response to anthracycline-based preoperative chemotherapy in high-risk primary breast cancer. Breast Cancer Res Treat 2010; 120: 481-489

[67] Press MF, Sauter G, Buyse M et al. Alteration of topoisomerase II-alpha gene in human breast cancer: association with responsiveness to anthracycline-based chemotherapy. J Clin Oncol 2011; 29: 859-867

[68] Fasching PA, Weihbrecht S, Haeberle L et al. HER2 and TOP2A amplification in a hospital-based cohort of breast cancer patients: associations with patient and tumor characteristics. Breast Cancer Res Treat 2014; 145: 193-203

[69] Janni W, Nitz U, Rack BK et al. Pooled analysis of two randomized phase III trials (PlanB/SuccessC) comparing six cycles of docetaxel and cyclophosphamide to sequential anthracycline taxane chemotherapy in patients with intermediate and high risk HER2-negative early breast cancer ( $n=5,923)$. J Clin Oncol 2018; 36: 522-522. doi:510.1200/ JCO.2018.1236.1215_suppl.1522

[70] Nitz U, Gluz O, Clemens M et al. West German Study PlanB Trial: Adjuvant Four Cycles of Epirubicin and Cyclophosphamide Plus Docetaxel Versus Six Cycles of Docetaxel and Cyclophosphamide in HER2-Negative Early Breast Cancer. J Clin Oncol 2019; 37: 799-808

[71] Mobus V. Adjuvant Dose-Dense Chemotherapy in Breast Cancer: Standard of Care in High-Risk Patients. Breast Care (Basel) 2016; 11: 8-12

[72] Early Breast Cancer Trialists' Collaborative Group (EBCTCG). Increasing the dose intensity of chemotherapy by more frequent administration or sequential scheduling: a patient-level meta-analysis of 37298 women with early breast cancer in 26 randomised trials. Lancet 2019; 393: 1440-1452. doi:10.1016/S0140-6736(18)33137-4

[73] Poggio F, Bruzzone M, Ceppi M et al. Platinum-based neoadjuvant chemotherapy in triple-negative breast cancer: a systematic review and meta-analysis. Ann Oncol 2018; 29: 1497-1508

[74] Early Breast Cancer Trialists' Collaborative Group (EBCTCG). Long-term outcomes for neoadjuvant versus adjuvant chemotherapy in early breast cancer: meta-analysis of individual patient data from ten randomised trials. Lancet Oncol 2018; 19: 27-39

[75] Masuda N, Lee S], Ohtani S et al. Adjuvant Capecitabine for Breast Cancer after Preoperative Chemotherapy. N Engl J Med 2017; 376: 2147-2159

[76] von Minckwitz G, Huang CS, Mano MS et al. Trastuzumab Emtansine for Residual Invasive HER2-Positive Breast Cancer. N Engl J Med 2018. doi:10.1056/NEJMoa1814017

[77] von Minckwitz G, Bear H, Bonnefoi H et al. Abstract OT2-6-11: PENELOPE: Phase III study evaluating palbociclib (PD-0332991), a cyclin-dependent kinase (CDK) 4/6 inhibitor in patients with hormone-receptorpositive, HER2-normal primary breast cancer with high relapse risk after neoadjuvant chemotherapy (GBG-78/BIG1-13). Cancer Res 2013. doi:10.1158/0008-5472.SABCS13-OT2-6-11 